\title{
Degradation of Phenol with Fenton-like Treatment by Using Heterogeneous Catalyst (Modified Iron Oxide) and Hydrogen Peroxide
}

\author{
Sihoon Lee, Jooyub Oh, and Yoonchang Park ${ }^{*}$ \\ Department of Chemistry, Sungkyunkwan University, Suwon 440-746, Korea. *E-mail: sonate@paran.com \\ Received April 24, 2005
}

\begin{abstract}
Goethite, hematite, magnetite and synthesized iron oxide are used as catalysts for Fenton-type oxidation of phenol. The synthesized iron oxides were characterized by X-ray diffraction (XRD), BET, X-ray photoelectron spectroscopy (XPS), and electron paramagnetic resonance (EPR). The catalytic activity of these materials is classified according to the observed rate of phenol oxidation. The effectiveness of the catalysts followed the sequence: ferrous ion $>$ synthesized iron oxide $>>$ magnetite hematite $>$ goethite. According to these results, the most effective iron oxide catalyst had the structure similar to natural hematite. The surface oxidation state of the catalyst was between magnetite and hematite $(+2.5 \sim+3.0)$. Phenol degraded completely in 40 min at neutral $\mathrm{pH}(\mathrm{pH}=7)$. Soluble ferric and ferrous ions were not detected in the filtrate from Fenton reaction solution by AAS. The formation of hydroxyl radicals was confirmed by EPR.
\end{abstract}

Key Words : Fenton, Heterogeneous catalyst, AOPs, Hyperfine splitting constant

\section{Introduction}

Advanced oxidation processes (AOPs) show potential for the treatment of toxic contaminants in waters and wastewaters. Hydrogen peroxide is safe, efficient, easy to use and suitable for wide usage on contamination prevention. ${ }^{1}$ However, it is not an efficient oxidant for most organic substances of interest because its catalyzed rate of reaction with most organics is too slow. Accordingly, hydrogen peroxide is often applied in combination with UV light, iron salts or ozone to produce hydroxyl radicals which react with most organics in diffusion controlled rates. ${ }^{2,3}$

In the Fenton reaction, ferrous salts such as $\mathrm{FeSO}_{4} \cdot \mathrm{H}_{2} \mathrm{O}$ are reacted with hydrogen peroxide $\left(\mathrm{H}_{2} \mathrm{O}_{2}\right)$ to generate $\mathrm{OH} \cdot{ }^{4-11}$

$$
\mathrm{Fe}^{2+}+\mathrm{H}_{2} \mathrm{O}_{2} \rightarrow \mathrm{Fe}^{3+}+\mathrm{OH} \bullet+\mathrm{OH}^{-}
$$

Fenton's reagent (generally, a mixture of reduced metal ions $+\mathrm{H}_{2} \mathrm{O}_{2}$ in modern usage) is an effective and simple oxidant for various types of organic contaminants. Contaminants may be oxidized into biologically degradable matter by adding hydrogen peroxide, and oxygen produced from hydrogen peroxide enhances the decomposition abilities of microorganisms. The main reactions of the Fenton system: $:^{4-11}$

$$
\begin{aligned}
& \mathrm{Fe}^{2+}+\mathrm{H}_{2} \mathrm{O}_{2} \rightarrow \mathrm{Fe}^{3+}+\mathrm{OH} \bullet+\mathrm{OH}^{-} \\
& \mathrm{Fe}^{3+}+\mathrm{H}_{2} \mathrm{O}_{2} \rightarrow \mathrm{Fe}^{2+}+\mathrm{HO}_{2} \bullet+\mathrm{H}^{+} \\
& \mathrm{Fe}^{3+}+\mathrm{HO}_{2} \bullet \rightarrow \mathrm{Fe}^{2+}+\mathrm{O}_{2}+\mathrm{H}^{+} \\
& \mathrm{OH} \bullet+\mathrm{H}_{2} \mathrm{O}_{2} \rightarrow \mathrm{HO}_{2} \bullet+\mathrm{H}_{2} \mathrm{O} \\
& \mathrm{OH} \bullet+\text { contaminants } \rightarrow \text { products }
\end{aligned}
$$

Because ferrous ions are often found in groundwater, this method has recently been applied to treat contaminated soil. $^{12,13}$ Watts et al. applied the Fenton reaction to oxidize pentachlorophenol-contaminated soils (using ferric ions as the catalyst instead of ferrous ions). ${ }^{14}$ In doing so, hydroxyl radicals were produced and pentachlorophenol was oxidiz- ed. The most effective $\mathrm{pH}$ range for Fenton reaction was $\mathrm{pH}$ 3-5. . $^{15,16}$

Drawbacks of the Fenton process include (1) the exacting $\mathrm{pH}$ requirement; and (2) ferric ions produced under Fenton treatment generate a significant amount of ferric hydroxide sludge that requires further separation and disposal. ${ }^{17,18}$ Many researchers have recently reported on the use of heterogeneous catalysts with hydrogen peroxide as an alternative. ${ }^{14-17}$ Valentine et al. investigated the feasibility of applying metal oxides, particularly iron oxides as $\mathrm{H}_{2} \mathrm{O}_{2}$ activation catalysts. ${ }^{5}$ They observed an accelerated decomposition of hydrogen peroxide, and the concentration of a model contaminant, quinoline, decreased at neutral $\mathrm{pH}$. Sandy aquifer material has also been employed as a $\mathrm{H}_{2} \mathrm{O}_{2}$ activation catalyst to study the degradation of quinoline. ${ }^{13}$ Goethite has been used in the investigation of heterogeneous catalytic oxidation of chlorophenols by hydrogen peroxide. ${ }^{19}$

A disadvantage of using a heterogeneous catalyst is that the decomposition rate of organic contaminants is slower than in classic Fenton reaction using ferrous ions at acidic conditions ( $\mathrm{pH}=3-5)$.

This study reports the development of a new heterogeneous catalyst (modified iron oxide) to increase the rate of decomposition of organic contaminants. Phenol was chosen as the probe compound in this study. Modified iron oxide and other oxide catalysts were compared on their performance in the rate of decomposition of hydrogen peroxide, and oxidation of phenol under varying $\mathrm{pH}$ conditions.

\section{Experimental Section}

Materials. Iron(II) sulfate heptahydrate $\left(\mathrm{FeSO}_{4} \cdot 7 \mathrm{H}_{2} \mathrm{O}\right.$, 98\%), sodium hydroxide $(\mathrm{NaOH}, 98 \%)$, hydrochloric acid $(\mathrm{HCl}, 36.5 \%)$, perchloric acid $\left(\mathrm{HClO}_{4}, 60 \%\right)$, hydrogen peroxide $\left(\mathrm{H}_{2} \mathrm{O}_{2}, 30 \%\right)$ and phenol $\left(\mathrm{C}_{6} \mathrm{H}_{5} \mathrm{OH}, 99 \%\right)$ were obtained from Aldrich and used as received. Purified water 
was obtained by passing house-distilled water through a Milli-Q (Millipore) water purification system. This purified water $\left(18 \mathrm{M} \Omega^{-1}\right)$ was used for all experiments.

Catalyst preparation. A modified iron oxide catalyst was developed in the following manner.

$\mathrm{FeSO}_{4} \cdot 7 \mathrm{H}_{2} \mathrm{O}(5 \mathrm{~g})$ was dissolved in water $(50 \mathrm{~mL}) .3 \mathrm{M}$ aqueous $\mathrm{NaOH}$ was added dropwise, and the $\mathrm{pH}$ was adjusted to 9.0. This solution was agitated for 40 mins. A color change from red to reddish brown was observed. The precipitate was filtered, washed with water to ensure complete removal of the $\mathrm{NaOH}$ and sulfate ion $\left(\mathrm{SO}_{4}{ }^{2-}\right)$, and air-dried. The products were placed in a furnace (in air) with a temperature ramp of $2{ }^{\circ} \mathrm{Cmin}^{-1}$ at $400,600,800$ and 1000 ${ }^{\circ} \mathrm{C}$. The products were heated at each temperature for $2 \mathrm{~h}$. The temperature was then decreased at the same ramp rate to room temperature.

Analytical methods and catalyst characterization. The concentration of phenol was analyzed using HPLC (Waters 600E) equipped with Waters 486 tunable Absorbance Detector with a reverse phase Merck LiChropher ${ }^{\mathbb{B}}$ C-8 column $(25 \mathrm{~cm} \times 4 \mathrm{~mm} \mathrm{ID})$. The mobile phase was $60 \%$ methanol (Fisher) and 40\% deionized water. The flow rate was $1.0 \mathrm{~mL} / \mathrm{min}$ with an injection volume of $10 \mu \mathrm{L}$. The phenol concentration was determined by using a calibration curve obtained from solutions of known concentration.

The concentration of total ferric and ferrous ions was determined with an Atomic Absorbance Spectrometer (Perkin Elmer 5100PC). Surface area and average particle size were measured by a $\mathrm{N}_{2}$-BET meter (Micromeritics ASAP 2400) and a particle analyzer (Fritsch analysett 22) respectively. The structure of the catalysts was determined using a X-ray diffraction spectrometer (Rigaku DMAX-33). An X-ray photoelectron spectrometer (Escalab 220i) was used to measure surface oxidation state of catalyst. Hydrogen peroxide concentration was determined by a Merckquant ${ }^{\circledR}$ Peroxide Test (Merck), and hydroxyl radical generation was confirmed by electron paramagnetic resonance (Bruker ER302 X-band spectrometer).

Experimental procedures. All experiments were conducted at $25{ }^{\circ} \mathrm{C}$. A solution of phenol and hydrogen peroxide was prepared (initial concentration of phenol: $200 \mathrm{ppm}$ and $\mathrm{H}_{2} \mathrm{O}_{2}$ : $400 \mathrm{ppm}$ ) at $\mathrm{pHs}$ of 3, 5, 7, 9 and 11 (using $1 \mathrm{M}$ $\mathrm{HClO}_{4}$ and $1 \mathrm{M} \mathrm{NaOH}$ ). The solution was added to a 250 $\mathrm{mL}$ flask. Catalysts (goethite, hematite, magnetite, synthesized iron oxides, and ferrous ion) were added to each solution to initiate the reaction. Catalyst dosage was 0.1 $w t \%$, with the exception of ferrous ion (ferrous ion: 0.13 $\mathrm{mM})$. The hydrogen peroxide concentration was $400 \mathrm{ppm}$. Specified above samples were taken in 5 min intervals and filtered through $0.45 \mu \mathrm{m}$ membrane filters to separate catalyst particles from the solutions. The filtrate was then analyzed for hydrogen peroxide, phenol and total ferric and ferrous ions. The $\mathrm{pH}$ of the filtrate was also noted.

A solution of hydrogen peroxide and water were prepared with an adjusted $\mathrm{pH}$ of 3 using $1 \mathrm{M} \mathrm{HClO}_{4}$ and $1 \mathrm{M} \mathrm{NaOH}$. The solution and $0.1 \mathrm{wt} \%$ catalyst were placed into the EPR cell, and mixed well. Upon equilibration, the cell was placed into the cavity immediately and spectra were acquired by EPR at $77 \mathrm{~K}$.

\section{Results and Discussion}

Degradation of phenol with different iron oxides and hydrogen peroxide. The initial $\mathrm{pH}$ for the reaction was 3 and the same concentration of $400 \mathrm{ppm}$ hydrogen peroxide, $200 \mathrm{ppm}$ phenol and $0.1 \mathrm{wt} \%$ iron oxides were used in these experiments. The experimental observations are shown in Figure 1. According to these results, the catalytic activity for phenol decomposition followed the sequence: ferrous ion $\left(k_{\mathrm{obs}}=5.19 \times 10^{-1} \mathrm{~min}^{-1}\right)>$ synthesized iron oxide $\left(k_{\mathrm{obs}}=\right.$ $\left.3.94 \times 10^{-1} \mathrm{~min}^{-1}\right)>>$ magnetite $\left(k_{\mathrm{obs}}=1.21 \times 10^{-1} \mathrm{~min}^{-1}\right)>$ hematite $\left(k_{\mathrm{obs}}=1.16 \times 10^{-1} \mathrm{~min}^{-1}\right)>$ goethite $\left(k_{\mathrm{obs}}=1 \times 10^{-2}\right.$ $\left.\min ^{-1}\right)$. Magnetite was a more effective catalyst than goethite or hematite. Modified iron oxide synthesized in lab and calcined at $600{ }^{\circ} \mathrm{C}$ was a similar effectiveness to ferrous ion at $\mathrm{pH}=3$.

Pseudo-first-order rate law with respect to the phenol concentration is plotted versus initial reaction times, and rate constants for the decomposition of phenol are determined from Figure 2. The slope of these lines provides the decomposition rate constant. In the presence of $0.1 \mathrm{wt} \%$ goethite which has been used frequently as the catalyst of Fenton-like reaction, phenol was degraded with the first order rate constant $(k) 1 \times 10^{-2} \mathrm{~min}^{-1}$. In the case of the other iron oxides hematite and magnetite, the decomposition rates were $1.16 \times 10^{-1} \mathrm{~min}^{-1}$ and $1.21 \times 10^{-1} \mathrm{~min}^{-1}$, respectively. However, a significant rate enhancement was attained from the solution in the presence of $0.1 \mathrm{wt} \%$ modified iron oxide calcined at $600{ }^{\circ} \mathrm{C}$, synthesized in lab $\left(k_{\mathrm{obs}}=3.94 \times 10^{-1}\right.$ $\mathrm{min}^{-1}$ ). This corresponds to 3-40 times increase in decomposition of phenol by comparing to other oxide (goethite, hematite and magnetite).

The decomposition of phenol was also carried out with 0.1

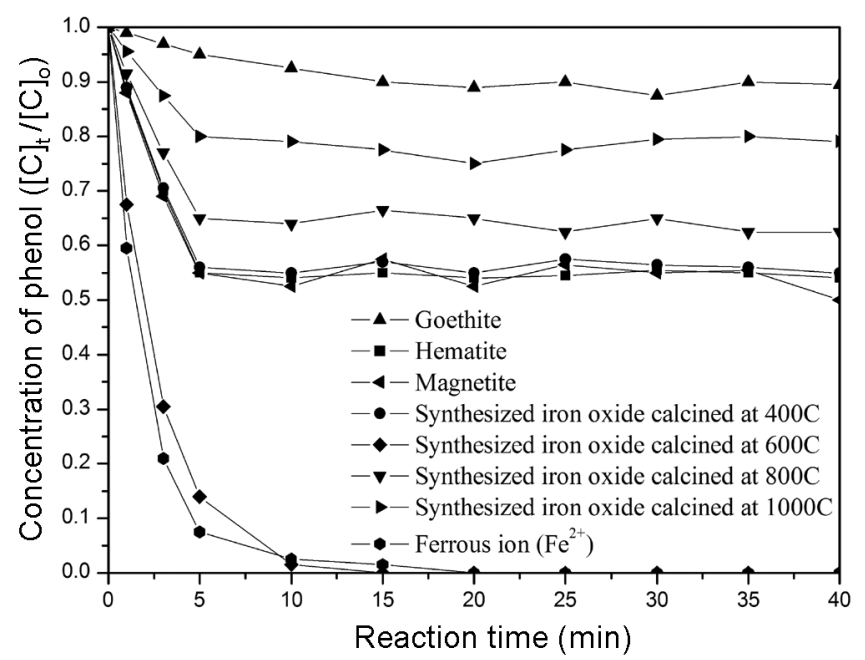

Figure 1. Iron oxide synthesized from $\mathrm{FeSO}_{4}$ calcined at $600{ }^{\circ} \mathrm{C}$ was more effective catalyst than other iron oxides. (Initial $\mathrm{pH}=3$, Concentration of phenol and hydrogen peroxide is 200 and 400 ppm respectively). 


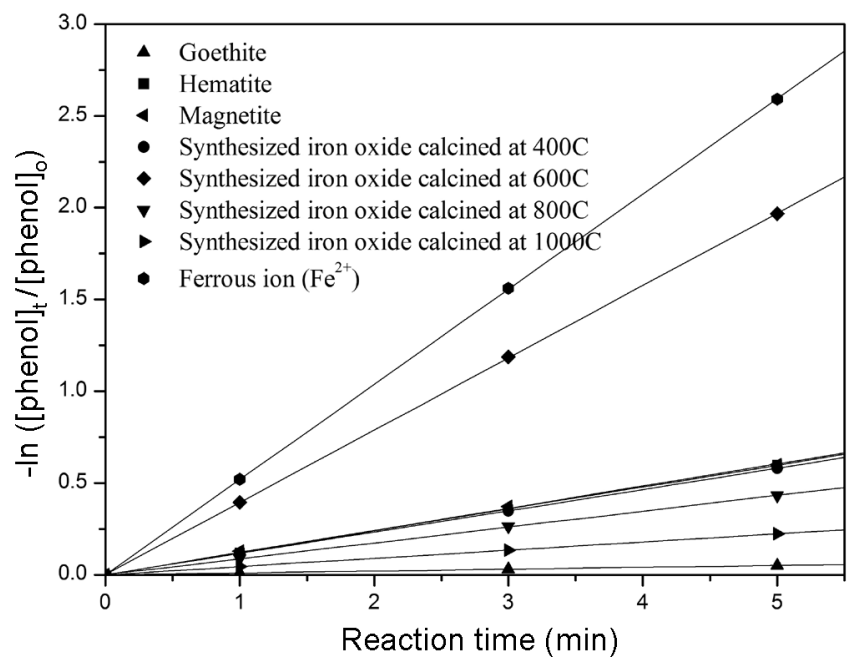

Figure 2. Phenol degrades much more quickly in the over presence of ferrous ion $\left(\mathrm{Fe}^{2+}\right)$ or iron oxide calcined at $600^{\circ} \mathrm{C}$ than any other condition. (Initial $\mathrm{pH}=3$, Concentration of phenol and hydrogen peroxide is 200 and 400 ppm respectively).

$\mathrm{wt} \%$ modified iron oxides calcined at the other temperatures $\left(400,800\right.$ and $\left.1000{ }^{\circ} \mathrm{C}\right)$ for the comparison purpose under otherwise identical conditions. It can be seen from Figure 2 that the decomposition of phenol with the most effective catalyst calcined at $600{ }^{\circ} \mathrm{C}$ is 3-8 times faster than that with catalysts that has been calcined at the other temperatures. Because iron oxide calcined at $400{ }^{\circ} \mathrm{C}$ was ferric hydroxide forms yet, the decomposition rate for phenol was slow. Iron oxides calcined at $800,1000{ }^{\circ} \mathrm{C}$ were hematite form and had lower surface areas and larger particle sizes than commercial hematite. Therefore, these iron oxides are expected to have low decomposition rates for phenol. Phenol in the presence of $0.13 \mathrm{mM}$ ferrous ion a decomposition rate of $5.19 \times 10^{-1}$ $\min ^{-1}$ was determined.

Table 1 shows the surface area normalized rate constants, $k_{\text {suf }}$

$$
k_{\text {suf }}=k_{\text {obs }} / S A_{V}
$$

where $S A_{v}=$ surface area per unit of water volume. Accordingly to results, modified iron oxide calcined at 1000 ${ }^{\circ} \mathrm{C}$ has the highest surface area rate constant $\left(4.4 \times 10^{-1} \mathrm{~min}^{-1}\right.$ $\left.\left(\mathrm{m}^{2} / \mathrm{L}\right)^{-1}\right)$, since this iron oxide has the smallest surface area. Goethite has the largest surface area, so surface area rate

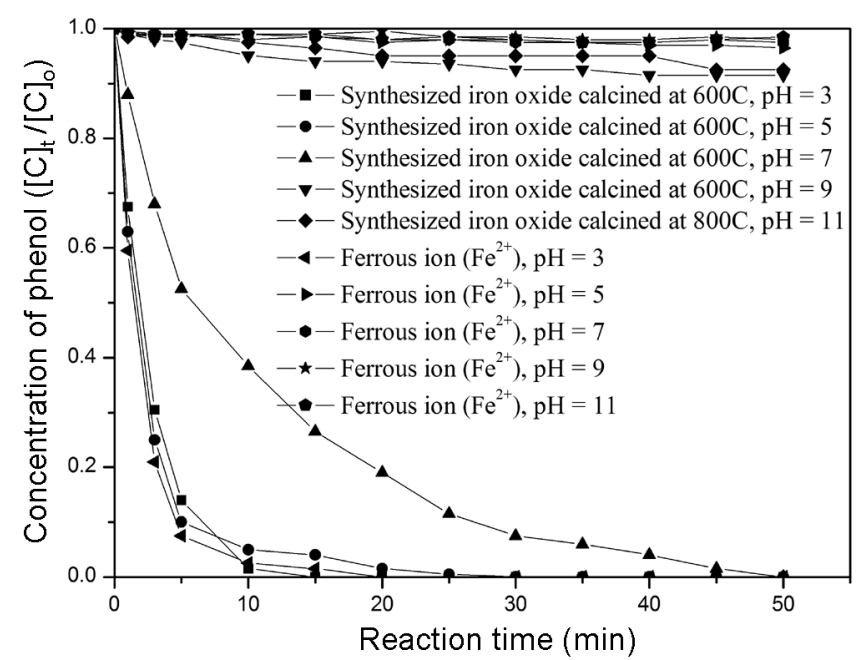

Figure 3. Ferrous ion degraded phenol below $\mathrm{pH}=3$ while synthesized iron oxide calcined at $600{ }^{\circ} \mathrm{C}$ degraded phenol up to $\mathrm{pH}=7$. (Concentration of phenol and hydrogen peroxide is 200 and 400 ppm respectively).

constant is $4.65 \times 10^{-5} \mathrm{~min}^{-1}\left(\mathrm{~m}^{2} / \mathrm{L}\right)^{-1}$. The surface rate constant of modified iron oxide calcined at $600{ }^{\circ} \mathrm{C}$ (the highest rate constant, $k_{\mathrm{obs}}=3.94 \times 10^{-1} \mathrm{~min}^{-1}$ ) has $3.05 \times 10^{-2}$ $\min ^{-1}\left(\mathrm{~m}^{2} / \mathrm{L}\right)^{-1}$.

Solution $\mathrm{pH}$ is a very important factor for the Fenton reaction. It is well known that the most effective $\mathrm{pH}$ range for the Fenton reaction is at $\mathrm{pH} 3-5 .^{15,16}$ In order to overcome the limitation of low $\mathrm{pH}$ in the classic Fenton reaction, the experiments were carried out at several $\mathrm{pH}$ with a new heterogeneous catalyst. Figure 3 shows the decomposition of phenol with modified iron oxide calcined at $600{ }^{\circ} \mathrm{C}$, synthesized in lab and ferrous ion at several $\mathrm{pH}$ values $(3,5$, 7, 9 and 11).

According to these results, the significant decomposition of phenol with ferrous ion was not observed except at $\mathrm{pH}=$ 3. Phenol disappeared in 20 mins by Fenton treatment with ferrous ion at $\mathrm{pH}=3$. As $\mathrm{pH}$ of the solution increased, ferric hydroxide $\left(\left[\mathrm{Fe}(\mathrm{OH})_{2}\right]^{+}\right)$was formed.$^{20}$ Ferric hydroxide is an obstruction of Fenton treatment and does not decompose hydrogen peroxide effectively. Eventually ferrous ion does not produce hydroxyl radical and does not degrade organic compounds, while modified iron oxide synthesized in lab can degrade phenol at neutral $\mathrm{pH}(\mathrm{pH}=7)$. Since synthesized

Table 1. Decomposition rate constants of phenol and hydrogen peroxide in presence of iron oxides at $\mathrm{pH} 3.0$ (Initial concentration of phenol and hydrogen peroxide is 200 and 400 ppm respectively)

\begin{tabular}{lcrrr}
\hline \multicolumn{1}{c}{ Catalyst } & $k_{\mathrm{obs}}\left(\mathrm{min}^{-1}\right)$ & $k_{\mathrm{H} 2 \mathrm{O} 2}\left(\mathrm{~min}^{-1}\right)$ & $k_{\mathrm{suf}}\left(\mathrm{min}^{-1}\left(\mathrm{~m}^{2} / \mathrm{L}\right)^{-1}\right)$ & $k_{\mathrm{H} 2 \mathrm{O} 2} / k_{\mathrm{obs}}$ \\
\hline Modified iron oxide calcined at $400^{\circ} \mathrm{C}$ & $1.192 \times 10^{-1}$ & $1.2 \times 10^{-2}$ & $2.5 \times 10^{-3}$ & $1 \times 10^{-1}$ \\
Modified iron oxide calcined at $600^{\circ} \mathrm{C}$ & $3.94 \times 10^{-1}$ & $1.96 \times 10^{-1}$ & $3.05 \times 10^{-2}$ & $4.97 \times 10^{-1}$ \\
Modified iron oxide calcined at $800^{\circ} \mathrm{C}$ & $8.6 \times 10^{-2}$ & $8 \times 10^{-3}$ & $3.91 \times 10^{-2}$ & $9.3 \times 10^{-2}$ \\
Modified iron oxide calcined at $1000^{\circ} \mathrm{C}$ & $4.4 \times 10^{-2}$ & $5 \times 10^{-3}$ & $4.4 \times 10^{-1}$ & $1.14 \times 10^{-1}$ \\
Ferrous ion & $5.19 \times 10^{-1}$ & $2.32 \times 10^{-1}$ & - & $4.47 \times 10^{-1}$ \\
Goethite & $1 \times 10^{-2}$ & $2 \times 10^{-3}$ & $4.65 \times 10^{-5}$ & $2 \times 10^{-1}$ \\
Hematite & $1.16 \times 10^{-1}$ & $1.1 \times 10^{-2}$ & - & $9.5 \times 10^{-2}$ \\
Magnetite & $1.21 \times 10^{-1}$ & $1.5 \times 10^{-2}$ & - & $1.24 \times 10^{-1}$ \\
\hline
\end{tabular}




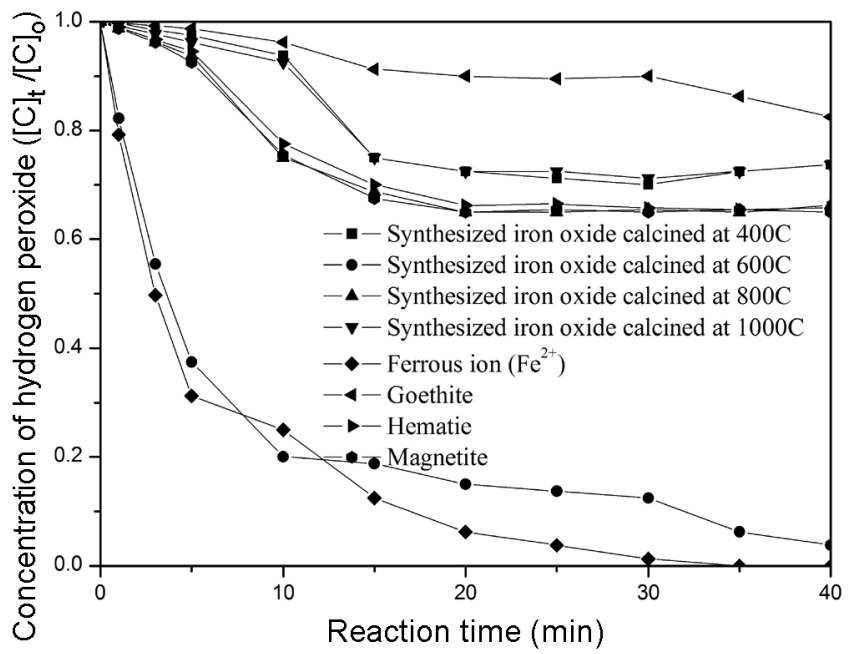

Figure 4. Decomposition of hydrogen peroxide at different iron oxides. (Initial $\mathrm{pH}=3$, Concentration of phenol and hydrogen peroxide is 200 and 400 ppm respectively).

iron oxide is essentially insoluble ferric hydroxide is not formed. Therefore, this catalyst can degrade phenol effectively up to neutral $\mathrm{pH}$. However, above neutral $\mathrm{pH}$ this catalyst could not degrade phenol. We speculate hydroxyl radicals react with hydroxide ion $\left(\mathrm{OH}^{-}\right)$or hydrogen peroxide $\left(\mathrm{H}_{2} \mathrm{O}_{2}\right)$ faster than organic compounds above neutral $\mathrm{pH}$, and then the decomposition rate for phenol is decreased. ${ }^{21}$

Fenton treatment uses hydrogen peroxide as an oxidant. The decomposition rate for hydrogen peroxide by a catalyst is very important factor. ${ }^{13}$ Figure 4 shows the decomposition of hydrogen peroxide using different iron sources. Decomposition of hydrogen peroxide was consistent with degradation of phenol. The decomposition rates for hydrogen peroxide with ferrous ion and synthesized iron oxide were much higher than those of other iron sources (goethite, hematite and magnetite). As the decomposition of hydrogen peroxide increased, the degradation of phenol increased. $k_{\mathrm{H}_{2} \mathrm{O}_{2}} / k_{\text {obs }}$ of modified iron oxide calcined at $600{ }^{\circ} \mathrm{C}$ and ferrous ion is 0.497 and 0.447 . These materials were more efficient than other iron oxides (goethite, magnetite, hematite). Previous researchers reported sequential addition of $\mathrm{H}_{2} \mathrm{O}_{2}$ would provide a more efficient and economical way of treatment. ${ }^{22}$

Characterization of catalyst. Crystallographic characterization was performed with XRD. According to the XRD patterns in Figure 6, the two syntheses gave either hematite or amorphous structures. The sample calcined at $400{ }^{\circ} \mathrm{C}$ was amorphous form, and samples calcined at 600, 800 and 1000 ${ }^{\circ} \mathrm{C}$ were hematite forms. The most effective catalyst for degradation of phenol is iron oxide calcined at $600{ }^{\circ} \mathrm{C}$. This catalyst has a hematite structure, but a peak intensity is lower than commercial hematite (from Aldrich).

Because Fenton-like treatment using heterogeneous catalysts is a surface reaction, the surface oxidation state of the catalyst is very important. In order to confirm the surface oxidation state of synthesized iron oxide, the surface oxida-

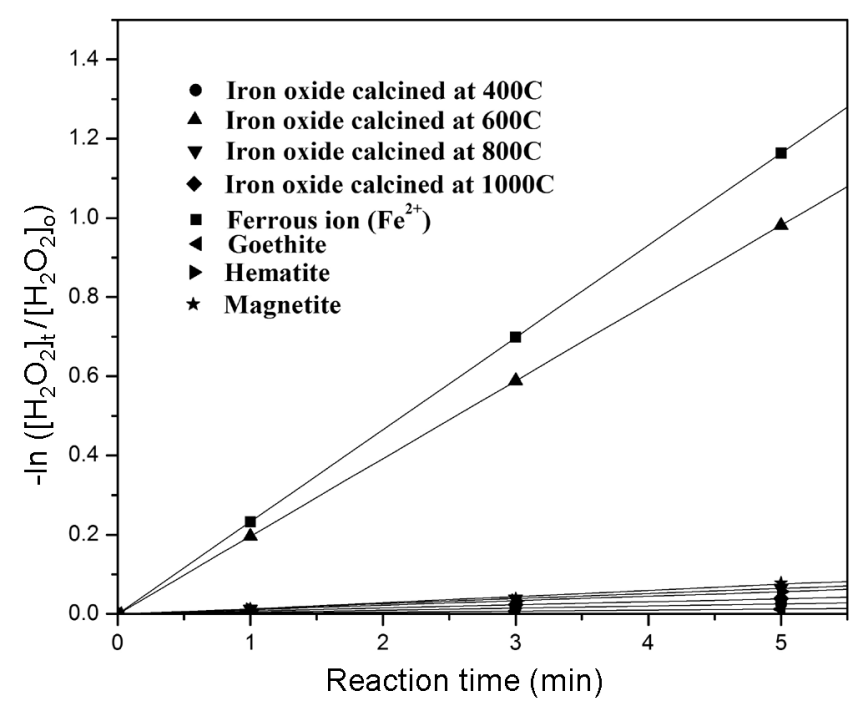

Figure 5. $\mathrm{H}_{2} \mathrm{O}_{2}$ decomposes much more quickly in the over presence of Ferrous ion $\left(\mathrm{Fe}^{2+}\right)$ or iron oxide calcined at $600{ }^{\circ} \mathrm{C}$ than any other condition (Initial $\mathrm{pH}=3$, Concentration of phenol and hydrogen peroxide is 200 and $400 \mathrm{ppm}$ respectively).

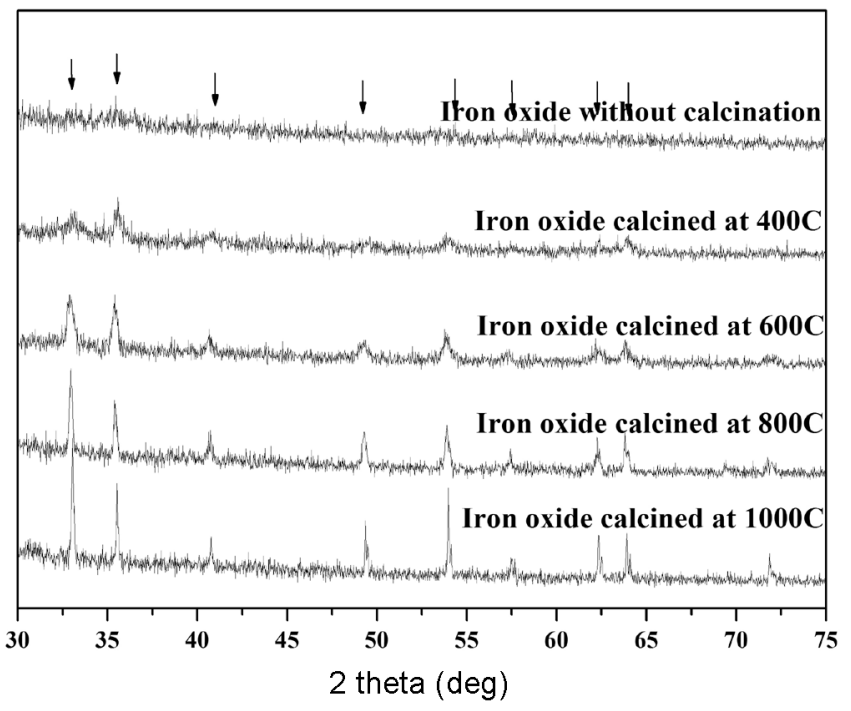

Figure 6. X-ray diffraction patterns of modified iron oxide. (arrows show hematite peaks.)

tion state of catalyst was measured by X-ray photoelectron spectrometer (XPS). Figure 7 shows XPS spectra of different iron oxides (goethite, magnetite, hematite, synthesized iron oxide). Binding energies of iron $\left(2 \mathrm{P}_{1 / 2}, 2 \mathrm{P}_{3 / 2}\right)$ in goethite and hematite are $724.9 \mathrm{eV}$ and $711.4 \mathrm{eV}$; and binding energies of iron in magnetite are $722.3 \mathrm{eV}$ and $708.2 \mathrm{eV}$. According to these results, we observed that binding energies of iron in synthesized iron oxide in lab (the most effective catalyst) shifted to low energy states. These binding energies were between those of hematite (or goethite) and magnetite.

The oxidation state of iron in goethite and hematite is +3 and that of iron in magnetite is +2 . Therefore, the surface oxidation state of synthesized iron oxide in lab is between 


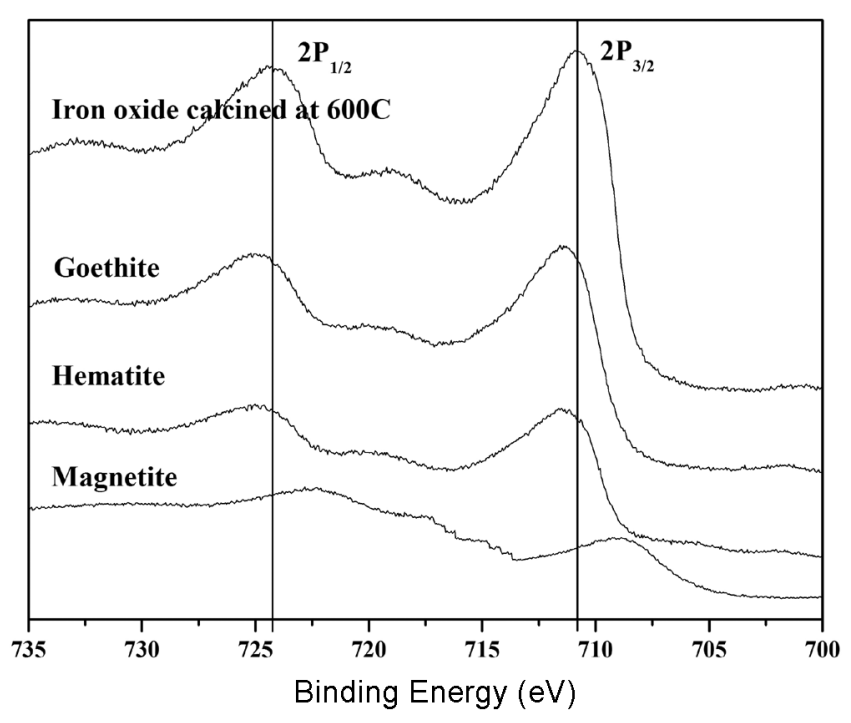

Figure 7. XPS spectra of Iron oxides.

+2 and $+3(c a .+2.8)$. Many researchers reported that magnetite is a more effective catalyst for Fenton-like treatment than goethite and hematite. ${ }^{12,22-24}$ Magnetite has a combination of +2 iron and +3 iron atomics giving an average oxidation state of +2.5 . The combination of oxidation states +2 and +3 in magnetite aids to increase decomposition of hydrogen peroxide, and enhance decomposition of organic contaminants. ${ }^{2,23}$ Average surface oxidation state of synthesized iron oxide in lab was halfway between +2.5 and +3 .0. It was speculated that mixing the oxidation states (average surface oxidation state was $c a$. +2.8 ) of the catalyst surface enhanced the efficiency of Fenton-like treatment.

Table 2 shows surface areas and particle sizes of iron oxides calcined at several temperatures. As the temperature of calcination increased, BET surface area decreased and the size of particle increased. Lu reported that the most effective goethite catalyst had $215 \mathrm{~m}^{2} / \mathrm{g}$ surface area and $44-74 \mu \mathrm{m}$ of diameter. ${ }^{19}$ The most effective catalyst synthesized in the lab has $12.9 \mathrm{~m}^{2} / \mathrm{g}$ surface area and $50.7 \mu \mathrm{m}$ diameter. This catalyst has similar size but smaller surface area than goethite used by Lu. ${ }^{25}$ These phenomena indicate that this catalyst is less porous than goethite used by $\mathrm{Lu}$.

Previous researchers evaluated different iron oxides under the same conditions, but found differences in the degrada-

Table 2. BET surface area and mean diameter of iron oxides calcined at several temperatures

\begin{tabular}{ccc}
\hline $\begin{array}{c}\text { Calcined temperature } \\
\left({ }^{\circ} \mathrm{C}\right)\end{array}$ & $\begin{array}{c}\text { BET surface area } \\
\left(\mathrm{m}^{2} / \mathrm{g}\right)\end{array}$ & $\begin{array}{c}\text { Mean diameter } \\
(\text { um })\end{array}$ \\
\hline Raw & 59.0 & 18.9 \\
400 & 46.8 & 36.3 \\
600 & 12.9 & 50.7 \\
800 & 2.2 & 95.2 \\
1000 & 0.1 & 166.1 \\
Goethite $^{19}$ & 215 & $44-74$ \\
\hline
\end{tabular}

tion rates of hydrogen peroxide and contaminants. ${ }^{12,14,22,26-28}$ Valentine et al. proposed the surface area of the iron oxide accounts for the difference in reaction activity. ${ }^{5}$ Huang et al. showed the decomposition rates of hydrogen peroxide by goethite, ferrihydrite, and hematite were all relatively similar when normalized to surface area. ${ }^{29}$ However, the decomposition of phenol and hydrogen peroxide using synthesized catalyst (surface area was smaller than goethite) was much better than goethite (Figure 1, 4). Therefore, in the case of synthesized iron oxide, this mechanism cannot be adopted. If the surface area of this synthesized iron oxide increased (more porous or less particle size) but its structure and surface oxidation state were kept constant, the degradation rate of organic contaminants will be enhanced. Currently, a more porous, smaller particle size, and larger surface area catalyst is being developed.

Previous researchers reported that ferrous ions are produced from the reductive dissolution of goethite as shown in (6). ${ }^{19,30} \mathrm{Lu}$ et al. reported that as goethite dissolution was increased, decomposition of organic compounds was increased. $^{25}$

In order to account for the reason why synthesized iron oxide was a more effective catalyst than other iron oxides (goethite, hematite, magnetite), measurements of the concentrations of iron ions in the reaction solution were attempted. As shown in Table 3, no ferrous ions or ferric ions were detected in the filtrate (reaction time: $60 \mathrm{~min}$ ). The detection limit of AAS used for this experiment was 0.1 ppm. When the synthesized iron oxide was used as the catalyst, phenol was degraded totally in $60 \mathrm{~min}$. These

Table 3. Generation of soluble iron (ferrous and ferric ions) from Iron oxides system. Detection limit: $0.1 \mathrm{ppm}$, reaction time: 60 min, N. D.: Not Detectable

\begin{tabular}{cc}
\hline Catalysts & Soluble iron $(\mathrm{ppm})$ \\
\hline Goethite & N.D. \\
Hematite & N.D. \\
Magnetite & N.D. \\
Synthesized iron oxide & N.D. \\
\hline
\end{tabular}
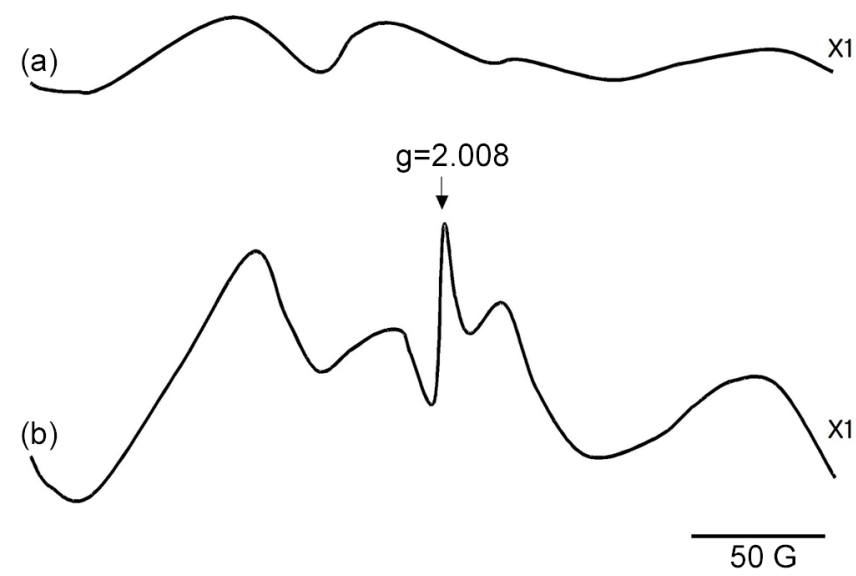

Figure 8. EPR spectra of synthesized iron oxide at 298 K. (a) addition of water (b) addition of hydrogen peroxide. 


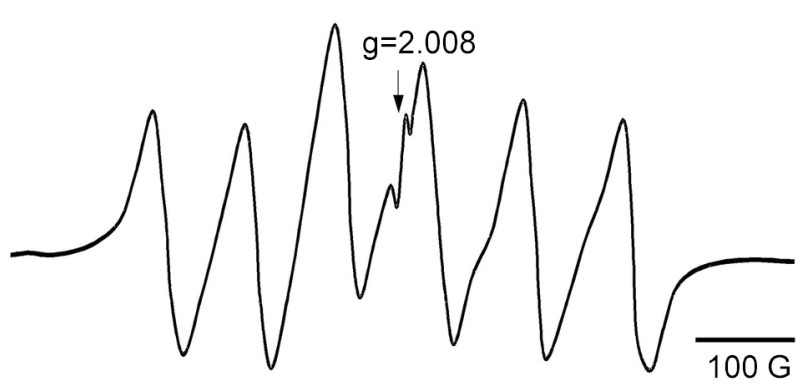

Figure 9. EPR spectra of synthesized iron oxide with hydrogen peroxide at $298 \mathrm{~K}$.

results were different from our prediction (iron ions could be detected). Reasoning for why synthesized iron oxide in lab was a more effective catalyst compared to other iron oxide (goethite, hematite, magnetite) could not be accounted for. Rather, these results may imply that the structure and the surface oxidation state of iron oxide are important factors.

Figure 8 and 9 show the EPR spectra of synthesized iron oxide. Before hydrogen peroxide was added, broad peaks due to iron oxide were observed. However, after the addition of hydrogen peroxide, 6 equally spaced peaks and a peak with the g-value of 2.008 , which is attributed to superoxide radical anion, were observed. ${ }^{31-35}$ Superoxide radical anion was generated from hydroxyl radical. Hydroxyl radical was confirmed indirectly. The intensity of these peaks increased as the concentration of hydrogen peroxide increased.

$$
\mathrm{OH} \bullet+\mathrm{H}_{2} \mathrm{O}_{2} \rightarrow \mathrm{HO}_{2} \bullet+\mathrm{H}_{2} \mathrm{O}
$$

The hyperfine splitting constant of these peaks is $9.5 \mathrm{mT}$, a value much larger than those of usual organic radicals. The hyperfine splitting constant $\left(\mathrm{a}_{\mathrm{H}}\right)$ of $\mathrm{OH} \bullet$ and $\mathrm{OOH} \bullet$ radical is $1.47 \mathrm{mT}$ and $1.17 \mathrm{mT}$, respectively. Therefore, the large hyperfine splitting constant is assigned to the hyperfine interaction between the electron spins of iron $\left(\mathrm{Fe}^{2+}\right.$ or $\left.\mathrm{Fe}^{3+}\right)$ and the nuclear spin of adjacent hydrogen atom $(I=1 / 2)$. Since the iron does not have an isotope with a nuclear spin of $I=1 / 2$, the isotropic hyperfine structure with 6 equally spaced peaks can arise from the hyperfine interaction of $\mathrm{Fe}(\mathrm{III})(\mathrm{S}=5 / 2)$ and adjacent $\mathrm{H}$ atom in the presence of zero field splitting. These results suggest that these peaks are caused by FeOOH that is formed on a synthesized iron oxide surface when hydrogen peroxide is added to iron oxide. Also, these results may imply that $\mathrm{Fe}(\mathrm{II})$ exists on the surface of the iron oxide catalyst in coincident with XPS results. Hydrogen peroxide reacts with $\mathrm{Fe}(\mathrm{II})$ on the iron oxide catalyst to produce $\mathrm{Fe}(\mathrm{III})$; hydroxyl radical, hydroxide ion and $\mathrm{Fe}(\mathrm{III})$ may react with hydroxide to form
FeOOH. Since no $\mathrm{Fe}^{2+}$ or $\mathrm{Fe}^{3+}$ ions were detected in the reaction solution mentioned previously, it is concluded that soluble iron ions do not contribute to the hyperfine splitting when hydrogen peroxide is added.

\section{References}

1. Elizardo, K. Fighting Pollution with Hydrogen Peroxide. Pollution Eng. 1991, 106.

2. Ince, N. H.; Stefan, M. I.; Bolton, J. R. J. Adv. Oxid. Technol. 1997, 2(3), 442 .

3. Legrini, O.; Oliveros, E.; Braun, A. M. Chem. Rev. 1993, 93, 671.

4. Fenton, H. J. H. Jour. Chem. Soc. (Brit.) 1894, 65, 899.

5. Valentine, R. L.; Wang, H. C. A. J. of Envir. Eng. 1998, 124, 31.

6. Safarzadeh-Amiri, A.; Bolton, J. R.; Cater, S. R. Water Res. 1997, 31, 787.

7. Barb, W. G. J. Chem. Soc. 1951, 47, 462.

8. Walling, C. Acc. Chem. Res. 1975, 8, 125.

9. Gallard, H.; De Laat, J.; Legube, B. Water Res. 1999, 33, 2929.

10. Chamarro, E.; Marco, A.; Esplugas, S. Water Res. 2001, 35, 1047.

11. Tang, W. Z.; Huang, C. P. Chemosphere 1996, 33, 1621.

12. Tyre, B. W.; Watts, R. J.; Miller, G. C. J. Environ. Qual. 1991, 20, 832 .

13. Miller, C. M.; Valentine, R. L. Water Res. 1995, 29(10), 2353.

14. Watts, R. J.; Udell, M. D.; Rauch, P. A. Waste and Haz. Mat. 1990, 7, 335 .

15. Roques, H. Chemical Water Treatment, Principles and Practice; VCH Publisher, Inc.: 1996.

16. Kwon, B. G.; Lee, D. S.; Kang, N. G.; Yoon, J. Y. Water Res. 1999, 33, 2110.

17. Chou, S.; Huang, C. Chemosphere 1999, 38, 2719.

18. Saltmiras, D. A.; Lemley, A. T. J. Agric. Food Chem. 2000, 48, 6149.

19. Lu, M. C. Chemosphere 2000, 40, 125.

20. Gallard, H.; De Laat, J.; Legube, B. Wat. Res. 1999, 33, 2929.

21. Kochany, E. L.; Sparh, G.; Harms, S. Chemosphere 1995, 30, 9.

22. Kong, S. H.; Watts, R. J.; Choi, J. H. Chemosphere 1998, 37, 1473.

23. Park, W. Y.; Kim, Y. S.; Kong, S. H. Theo. and Appl. of Chem. Eng. 1996, 2, 2179.

24. Watts, R. J.; Udell, M. D.; Kong, S. H.; Leung, S. W. Environ. Eng. Sci. 1999, 16, 93.

25. Lu, M. C.; Chen, J. N.; Huang, H. H. Chemosphere 2002, 46, 131.

26. Khan, A. J.; Watts, R. J. Water Air Soil Pollut. 1996, 88, 247.

27. Lin, S. S.; Gurol, M. D. Water Sci. Technol. 1996, 34, 57.

28. Watts, R. J.; Jones, A. P.; Chen, P. H.; Kenny, A. Water Environ. Res. 1997, 69, 269.

29. Huang, H. H.; Lu, M. C.; Chen, J. N. Water Res. 2001, 35, 2291.

30. Zinder, B.; Furrer, G.; Stumm, W. Geochimica Cosmochimica 1986, 50, 1861.

31. Anpo, M.; Shima, T.; Kubokawa, Y. Chem. Lett. 1985, 1799.

32. Jaeger, C. D.; Bard, A. J. Phys. Chem. 1979, 83, 3144.

33. Kuino, E.; Syuji, U.; Masaya, G.; Kenji, I.; Tsuneo, S.; Hiroshi, F.; Yoshifumi, K. Langumuir 1997, 13, 2803.

34. Howe, R. F.; Gratzel, M. J. Phys. Chem. 1985, 89, 4495.

35. Rajh, R.; Ostafin, A. E.; Micic, O. I.; Tiede, D. M.; Thurnauer, M. C. J. Phys. Chem. 1996, 100, 4538. 